\title{
Al'Adôlah
}

\section{PERDAMAIAN DALAM PERSPEKTIF ISLAM DAN KRISTEN}

\author{
Asy'ari \\ Institut Agama Islam Negeri Kediri \\ asyari.ri@iainkediri.ac.id
}

\begin{abstract}
The existence of Religion is a correction of behavioral problems that substantively cause tension, violence and even damage to the social fabric, or better known as tyranny. There is no religion established itself as a religion of violence and it is certain that all religions claim to be a religion of peace. But on the other hand, religion can lead to damage and even mass murder. Therefore, religious messages are ambivalent, whether religion is to solve problems or it is the source of problems. This ambivalence is emphasized with the rise of religious adherents by showing complex faces to interpret. The complex face is inseparable from the adherents of the religion itself, both Islam and Christian. Because the realization of religious adherents have the legitimacy of the text (the source of their religious teachings).
\end{abstract}

Keywords: Religion, Ambivalence, Jibad, Mission

\section{Pendahuluan}

Istilah "Peace" atau "damai sejahtera" sebenarnya dikenal oleh setiap bahasa dari bangsa manapun di dalam dunia ini. Baik itu "Shalom aleikhem" dalam bahasa Ibrani, Assalamu 'alaikum dalam bahasa Arab, "Rahayu" dalam bahasa Jawa, "Santi" bagi orang Bali, "Sancay" bagi orang Budha. ${ }^{1} \mathrm{Hal}$ ini membuktikan bahwa secara sosiologis-anthropologis setiap manusia dari bangsa manapun merindukan terjadi didalam dirinya suatu kondisi yang disebut diatas. Konsep mengenai "kedamaian" didalam setiap bangsa maupun didalam setiap ajaran agama adalah berbeda-beda dan bervariasi. Namun minimal memiliki satu kesamaan jika itu berhubungan diri sendiri dan keadaan lingkungannya. Persamaan itu adalah rasa damai itu dihubungkan dengan sifat ketenangan, tidak ada gangguan yang membuat hati menjadi gusar, takut, kuatir.

Dalam Islam istilah misi disebut juga dakwah. Dakwah dalam agama islam berarti mengajak, menyerukan, menyuarakan, serta melakukan upaya-upaya se-

${ }^{1}$ Ruslani, Masyarakat Kitab dan Dialog Antaragama: Studi Atas Pemikiran Mohammed Arkoun, (Yogyakarta:Yayasan Bentang Budaya, 2000), 153

DOI: https://doi.org/10.35719/aladalah.v22i1.9 
cara Islami, ${ }^{2}$ manusiawi yang efektif dalam rangka membentuk akhlak yang mulia, yaitu dengan membebaskan manusia dari berbagai macam belenggu yang memenjarai dirinya, sehingga manusia bebas merdeka, berperadaban, dinamis, kratif dan inovatif. Bahkan dalam surat lain dijelaskan cara mengajak manusia dengan cara sebaik-baiknya cara, yakni dengan cara hikmab/bijaksana, dengan cara ceramah, pelajaran yang baik lagi santun, dan jika yang diajak masih berdebat, maka debatlah mereka dengan cara sebaik-baiknya cara berdebat. ${ }^{3}$ Sehingga tidak ada dakwah dengan cara kekerasan dan perdamaian pun dapat terwujud dengan sendirinya.

Adanya berbagai agama dan aliran-aliran dalam agama, merupakan suatu kenyataan yang nampak di sekeliling kita. Dikelilingi kenyataan yang seperti ini, tidak pelak lagi bahwa setiap orang, kelompok agama maupun golongan dari apa dan manapun itu termasuk kita, dituntut untuk menyapa realitas serta mengambil sikap.

Dewasa ini, secara tidak langsung telah memberikan - meskipun hanya sedikit - pemahaman yang menegaskan bahwa agama dan masyarakat/realitas mempunyai makna yang begitu rigit bahkan keduanya sulit untuk dipisahkan. Agama dapat dikatakan adalah produk budaya. Misalnya dalam Islam, ada Islam Jawa, Islam Bali, Islam Aceh, bahkan beberapa tahun terakhir Islam Nusantara menjadi trending topik di berbagai media. Selain itu di dalam islam diwarnai adanya banyak aliran-aliran di dalamnya sebut saja misalnya Sunni, di dalamnya masih dibagi-bagi lagi dalam organisasi keagamaan yang mengatasnamakan dirinya suni, seperti Nahdlatul Ulama, Muhammadiyah, Persis, Perti, al Irsyad dst. Selain Sunni adapula aliran Syiah yang didalamnya juga beragam syiah Zaidiyah, ja'fariyah, Ismailiyah dst. Di dalam kekristenan pun juga demikian, ada Kristen katolik dan protestan (Pentakosta, Gereja Jawi Wetan dan seterusnya). Heterogenitas dalam tubuh agama akan berdampak pada pemaknaan pemahaman pemeluknya terhadap agamanya masing-masing, baik agama sebagai agama wahyu maupun agama sebagai produk sejarah. ${ }^{4}$

Agama dan manusia merupakan satu kesatuan, namun manusia diakui atau tidak, menjadi pemeluk agama yang paradoksal. Terkadang-kala ia ingin me-

2 maka disebabkan rahmat dari Allah-lah kamu berlaku lemah lembut terhadap mereka. Sekiranya kamu bersikap keras lagi berhati kasar, tentulah mereka menjauhkan diri dari sekelilingmu. Karena itu ma'afkanlah mereka, mohonkanlah ampun bagi mereka, dan bermusyawaratlah dengan mereka dalam urusan itu[246]. Kemudian apabila kamu telah membulatkan tekad, maka bertawakkallah kepada Allah. Sesungguhnya Allah menyukai orang-orang yang bertawakkal kepada-Nya. Lihat QS. Ali Imron (3): 159

${ }^{3}$ Serulah (manusia) kepada jalan Tuhan-mu dengan hikmah/bijaksana dan pelajaran yang baik dan bantahlah mereka dengan cara yang baik. Sesungguhnya Tuhanmu Dialah yang lebih mengetahui tentang siapa yang tersesat dari jalan-Nya dan Dialah yang lebih mengetahui orang-orang yang mendapat petunjuk. Lihat QS. An Nahl (16): 125.

${ }^{4}$ Pernyataan ini merupakan hasil refleksi terhadap pemikiran M. Atho' Mudzhar. Namun beliau tidak menjelaskan tentang agama, tapi menjelaskan tentang Islam. Jika meminjam bahasanya Amin Abdullah agama normative-historis 
nyendiri dengan eksklusivitasnya, tetapi pada saat yang sama ingin berada bersama yang lain. ${ }^{5}$ Pada mulanya, manusia menjadi diri sendiri ditempuh melalui cara meniru perilaku orang lain. Memulai menapak garis kehidupan adalah juga berarti meniru dan mengikuti pola pikir, kepercayaan dan perilaku generasi yang lebih dulu lahir, yang melingkupi dari manusia. Demikian halnya dengan agama. Setiap agama adalah unik, dan keunikan sebuah agama bukan berarti bahwa agama itu harus hidup secara eksklusif tanpa peduli kehadiran agama-agama lain yang juga memiliki keunikan, bahkan dirinya harus mengakui agama-agama yang sudah ada sebelumnya sebagaimana manusia mengakui akan adanya pendahulupendahulunya atau nenek moyangnya masing-masing.

Namun, eksklusifitas diri agama akan semakin memperuncing keadaan, yakni dengan adanya klaim kebenaran (truth claim) dan menafikan kebenaran pihak lain ${ }^{6}$ dari masing-masing agama. Setelah menyadari sepenuhnya sifat truth claim yang yang melekat pada hati sanubari pemeluk agama-agama semua di luar mereka akan dianggap salah. Potret inilah yang ingin didekonstruksi kosktruktif oleh penulis. Hal ini bisa ditelisik lebih jauh lagi, yakni dalam taraf yang paling otentis sekalipun semua agama, baik agama samawi maupun agama ardhi, niscaya memuat klaim kebenaran (truth claim) dan klaim keselamatan (salvation claim) sebagai karakter fundamentalis-nya yang transcendental dalam jagad imanen. Maka kemudian yang signifikan bukanlah terletak pada dogma otentik masngmasing agama, yang tentunya berasas pada ajaran penghargaan manusia. ${ }^{7}$

\section{Perdamaian dalam Perspektif Islam}

Perdamaian merupakan salah satu ajaran pokok dalam ajaran Islam. Kata Islam bisa diambil dari kata 'salama' yang berarti selamat dan juga 'silm dan salam' yang bermakna damai secara jelas menegaskan bahwa karakter dasar dari ajaran Islam adalah menyebarkan perdamaian. Dalam ungkapan teks agama, perdamaian sering dibahasakan dengan "al aman”. Dalam terminologi, al aman adalah sebuah kesepakatan untuk menghentikan peperangan dan pembunuhan dengan pihak musuh. Selain al aman masih ada beberapa istilah lain yang juga merujuk pada perdamaian, yakni al sulh, al hudnah, al mu'ahadah dan aqd al zimmah. Hal itu sebagaimana tertuang dalam ayat-ayat al-Qur'an. Secara jelas dalam QS. Al Furqan ayat 19 dinyatakan bahwa Islam datang sebagai agama yang membawa misi perdamaian dan dengan tegas mengharamkan kepada umat manusia melakukan kedzaliman, kapan dan dimana saja.

5 Ruslani, Masyarakat Kitab dan Dialog Antaragama: Studi Atas Pemikiran Mobammed Arkoun, (Yogyakarta:Yayasan Bentang Budaya, 2000), 153

${ }^{6}$ Hal tersebut terjadi karena sesungguhnya semua agama bermula dari “momen" khusus. Kecenderungan agama-agama memerhatikan yang khusus ini mengooptasi dan menghegemoni, sehingga mereduksi dan mengenyampingkan klaim spiritualitasnya yang universal, yang benar-benar rabmatan lil 'alamin

${ }^{7}$ Bernard Lewis, Kemelut Peradaban Kristen, Islam dan Yabudi, terj. Prismasophie (Yogyakarta: IRCiSod, 2001), 3 
Maka sesunggubnya mereka (yang disembah itu) telah mendustakan kamu tentang apa yang kamu katakan Maka kamu tidak akan dapat menolak (azab) dan tidak (pula) menolong (dirimu), dan barang siapa diantara kamu yang berbuat zalim, niscaya Kami rasakan kepadanya azab yang besar. ${ }^{8}$

Yang diharapkan Islam adalah adanya persamaan derajat diantara manusia. Tidak ada perbedaan antara satu golongan dengan golongan lain, semua memiliki hak dan kewajiban yang sama. Kaya, miskin, pejabat, pegawai, perbedaan kulit, etnis dan bahasa bukanlah alasan untuk mengistimewakan kelompok atas kelompok yang lain. Ini seperti termaktub dalam firmanNya:

Hai manusia, sesunggubnya Kami menciptakan kamu dari seorang laki-laki dan seorang perempuan dan menjadikan kamu berbangsa-bangsa dan bersuku-suku supaya kamu saling kenal mengenal. Sesunggubnya orang yang paling mulia diantara kamu disisi Allab ialah orang yang paling taqwa diantara kamu. Sesunggubnya Allah Maha Mengetahui dan Maha Mengenal. ${ }^{9}$

Bagi Islam yang membedakan derajat seseorang atas yang lainnya hanyalah ketakwaan. Yang paling bertakwa dialah yang paling mulia. Dengan adanya persamaan derajat itu, maka semakin meminimalisir timbulnya benih-benih kebencian dan permusuhan diantara manusia, sehingga semuanya dapat hidup rukun dan damai. Aspek lain yang Islam sangat tekankan demi terciptanya perd amaian dalam kehidupan sosial ditengah masyarakat adalah persoalan keadilan. Keadilan harus diterapkan bagi siapa saja walau dengan musuh sekalipun. Karena dengan ditegakkannya keadilan, maka tidak ada seorangpun yang merasa dikecewakan dan didiskriminasikan sehingga dapat merendam rasa permusuhan, dengan demikian konflik tidak akan terjadi. Allah berfirman dalam al-Qur'an:

Allah tidak melarang kamu untuk berbuat baik dan berlaku adil terhadap orangorang yang tiada memerangimu karena agama dan tidak (pula) mengusir kamu dari negerimu. Sesunggubnya Allah menyukai orang-orang yang berlaku adil. ${ }^{10}$

Hal lain yang juga tidak kalah pentingnya adalah persoalan kebebasan. Dalam hal ini Islam menjunjung tinggi kebebasan, terbukti dengan tidak adanya paksaan bagi siapa saja yang beragama, setiap orang bebas menentukan pilihannya. Dengan adanya kebebasan tersebut diharapkan tidak ada yang merasa terkekang hingga berujung pada munculnya kebencian.

Tidak ada paksaan untuk (memasuki) agama (Islam). Sesunggubnya telab jelas jalan yang benar dari pada yang sesat. Karena itu barang siapa yang ingkar kepada Thaghut dan beriman kepada Allah, maka sesunggubnya ia telah berpegang kepada bubul tali yang amat kuat yang tidak akan putus, dan Allab Maha Mendengar lagi Maba

\footnotetext{
${ }^{8}$ QS. Al Furqaan (25): 19

${ }^{9}$ QS. Al Hujarat (49): 13

${ }^{10}$ QS. Al Mumtahanah (60): 8
} 
Mengetabui. ${ }^{11}$

Islam juga menyeru kepada umat manusia untuk hidup rukun saling tolong menolong dalam melakukan perbuatan mulia dan mengajak mereka untuk saling bahu membahu menumpas kedzaliman di muka bumi ini, dengan harapan kehidupan yang damai dan sejahtera dapat terwujud sebagaimana firman Allah:

Dan tolong menolonglab kamu dalam (mengerjakan) kebaikan dan taqwa, dan jangan tolong-menolong dalam berbuat dosa dan pelanggaran. Dan bertaqwalah kamu kepada Allah, sesungguhnya Allah amat berat siksaNya. ${ }^{12}$

Islam juga menganjurkan kepada umatnya saling bertoleransi atas segala perbedaan yang ada, dalam rangka mencegah terjadinya pertikaian yang dapat merugikan semua pihak. Dalam firman-Nya:

Dan tidaklah sama kebaikan dan kejahatan. Tolaklah (kejabatan itu) dengan cara yang lebih baik, maka tiba-tiba orang yang antaramu dan antara dia ada permusuhan, seolah-olah menjadi teman yang sangat setia. Sifat-sifat yang baik itu tidak dianugrabkean melainkan kepada orang-orang yang sabar dan tidak dianugrabkan melainkan kepada orang-orang yang mempunyai keberuntungan yang besar. ${ }^{13}$

Dan masih banyak lagi ayat-ayat lain yang menjelaskan tentang arti pentingnya perdamaian, seperti larangan sombong (QS Luqman:18), anjuran untuk selalu berendah hati (QS Al Furqan:63), larangan merendahkan orang lain (QS Al Hujurat:11), berdebat dengan cara yang baik (QS Al Ankabut:46), dan lainlain.

Melihat teks-teks yang ada dalam al-Qur'an di atas, terlihat bahwa wajah Islam adalah agama yang mendambakan rasa damai dan menjadi penebar kedamaian. Dalam ayat diatas juga nampak universalitas Islam, semisal mengakui adanya pluralitas dan tidak memaksakan kehendak dalam beragama. Ayat-ayat ini memang tidak banyak menyebut kata perdamaian secara eksplisit, toh demikian ayat-ayat ini mengajarkan untk senantiasa berbuat baik dan menekankan adanya keseimbangan antara hubungan vertikal dengan Tuhan dan horizontal dengan sesama manusia dimana jika ajaran-ajaran ini dilakukan dengan baik tentu saja akan berimplikasi pada perdamaian dunia. Perintah ataupun anjuran berbuat baik kepada sesama adalah pintu utama dalam mewujudkan perdamaian. Perdamaian tidak akan tercipta dengan kezaliman karena kan selalu muncul perlawanan dari orang yang dizalimi.

Demikian konsep damai yang ada dalam al-Qur'an. Semua ajaran, perintah yang ada dalam ajaran Islam sebenarnya berujung pada terciptanya perdamaian dan keadilan di dunia. Kedatangan Islam ditengah bangsa Arab yang pada masa

${ }^{11}$ QS. Al Baqarah (2): 256

${ }_{12}$ QS. Al Maidah (5): 2

${ }^{13}$ QS. Al Fushshilat (41): 34-35 
itu jelas mempunyai misi perdamaian. Bangsa Arab yang saat itu terpecah belah ke dalam suku-suku dan suka berperang menjadi sebuah komunitas dibawah konsep keumatan. Sehingga semua manusia disamakan kedudukannya kecuali atas dasar iman. Disinilah kemudian kedatangan Islam membawa pergeseran yang cukup fundamental dalam system sosial bangsa Arab dari yang awalnya terpusat pada pertalian atas dasar kekeluargaan menjadi pertalian atas dasar keimanan dibawah konsep ummat.

Dan kalau ada dua golongan dari mereka yang beriman itu berperang hendaklah kamu damaikan antara keduanya! Tapi kalau yang satu melanggar perjanjian terhadap yang lain, hendaklah yang melanggar perjanjian itu kamu perangi sampai surut kembali pada perintah Allah. Kalau dia telah surut, daamaikanlah antara keduanya menurut keadilan, dan bendaklab kamu berlaku adil; sesunggubnya Allab mencintai orang-orang yang berlaku adil. ${ }^{14}$

Untuk era sekarang, tantangan lingkungan hidup, menjunjung tinggi harkat kemanusiaan (buman dignity), menghormati HAM adalah agenda bersama umat manusia tanpa pandang "bulu" keagamaannya. Melalui pintu etika ini, seluruh penganut agama-agama dapat tersentuh religiusitasnya, untuk tidak hanya menunjukkan dan menonjolkan having a religion-nya, tapi juga being religious-nya. Melalui pintu etika, dimensi spiritualitas keberagamaan terasa proming and challenging dan bukannya hanya terfokus pada dimensi formalitas lahiriah kelembagaan agama saja.

Tuntutan spiritualitas keberagamaan yang sejuk dan berwajah ramah, jauh lebih dibutuhkan manusia modern yang dihempas gelombang-gelombang besar konsumerisme-materialisme. Adanya tugas mulia umat beragama secara bersama-sama untuk menginterpretasikan ulang ajaran-ajaran agamanya untuk dikomunikasikan pada wilayah agama lain, sehingga mengurangi ketegangan antarumat beragama. Para teolog masing-masing agama dan juru dakwah serta misionaris semestinya memang "belajar" memahami relung-relung keberagamaan orang lain -bukan untuk tujuan pindah agama atau hegemoni cultural/etnosentisme- sehingga terbuka kesempatan untuk lebih bersifat saling memahami dan toleran. Dan sikap toleran ini tidak perlu dikhawatirkan akan menipiskan otentisitas keberagamaan yang semula dipeluknya. ${ }^{15}$

\section{Perdamaian dalam Perspektif Kristen}

Sebelum membahas misi perdamaian dalam "kacamata" Kristen, saya ingin menyampaikan berita beberapa waktu lalu tentang pernyataan Sri Paus Fransiskus (30/11), Paus asal Argentina sekaligus sebagai Pemimpin 1,2 miliar pemeluk Katolik Roma mengatakan bahwa:

\footnotetext{
${ }^{14}$ QS. Al Hujarat (49): 9

15 Ibid, hal. 155-156
} 
Asy'ari, Perdamaian dalam Perspektif Islam dan Kristen

"menyamakan Islam dengan kekerasan adalab salah dan ia menyeru para pemimpin Muslim untuk mengeluarkan kutukan secara global terhadap terorisme untuk menghapus stereotip tersebut." 16

Paus asal Argentina itu, sesering mungkin berusaha dan mencoba me mbina kerjasama dengan kelompok Islam moderat untuk membangun perdamaian dan melindungi umat Kristen di Timur Tengah, bahkan di lain kesempatan, beliau menyatakan dengan tegas bahwa "salah jika orang-orang bereaksi terhadap terorisme dengan marah pada Islam, dan salah juga jika menyamakan islam dengan kekerasan"."

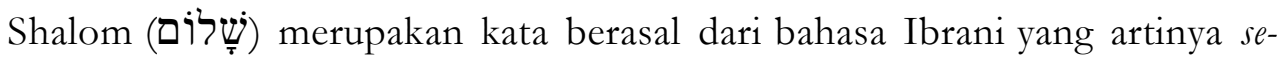
jabtera, Tidak ada yang hilang, Tidak ada perpecahan, kesehatan, dan kelengkapan, dan digunakan sebagai pengganti kata halo dan selamat tinggal. Kata ini dapat pula merujuk pada kesejahteraan antara dua entitas (terutama antara manusia dan Tuhan atau antara dua negara), atau untuk kesehatan, kesejahteraan atau keamanan dari individu atau sekelompok individu. Kata ini juga digunakan sebagai kata balasan dalam pengucapan kata halo atau selamat tinggal, dan dapat dijumpai penggunaannya di banyak gereja baik Kristen maupun Katolik. Kesamaannya yang sejenis dalam Arab adalah salam, Shlomo (r) dalam SyriakAssyria dan sälam dalam Bahasa Ethiopia yang berasal dari arti kata Ibrani yakni shin-lamed-mem (ש.ל. ש. Dalam latin bahasa Indonesia ditulis Syalom. ${ }^{18}$ Perka-

16 Pernyataan ini dapat dilihat di http://www.voaindonesia.com/content/paus-jangan-samakanislam-dengan-kekerasan/2540669.html, data ini diunduh pada tanggal 10 Januari 2015

${ }^{17}$ Lihat di http://www.koran-sindo.com/read/931730/149/paus-tolak-penyamaan-islam-dankekerasan-1417494455, data ini diunduh pada tanggal 10 Januari 2015

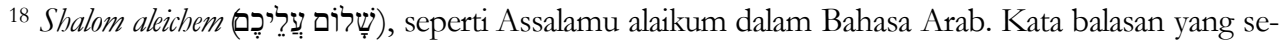

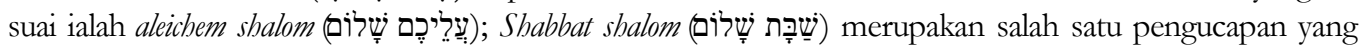
biasa digunakan pada hari Sabat. Kata ini paling banyak digunakan di kawasan-kawasan yang bermukim para penduduk Yahudi Mizrah, Yahudi Sephard, atau penduduk Israel yang berperilaku modern. Banyak komunitas Yahudi Ashkenaz di luar Yahudi menggunakan Gut shabbes dalam Bahasa Yiddish; $M a$

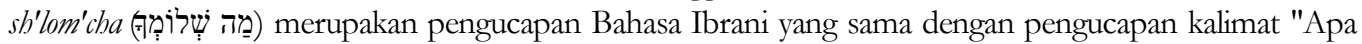
kabar?" dalam Bahasa Indonesia. Kata ini biasa digunakan oleh kaum laki-laki. Bentuk pengucapan untuk kaum perempuan adalah $M a$ sh'lomech? ata $M a$ sh'lomchen?. Untuk beberapa orang laki-laki yang bersifat

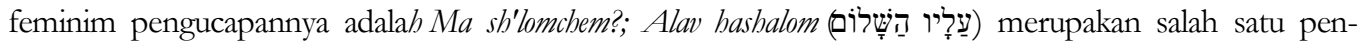
gungkapan yang digunakan oleh setengah komunitas Yahudi, terutama Yahudi Ashkenazi, setelah menyebutkan seseorang yang terhormat baginya yang telah meninggal dunia; Oseh shalom adalah sebagian daripada satu pengungkapan yang sering ditemukan dalam ayat-ayat penutup Liturgi Yahudi (termasuk birkat hamazon, kaddish dan doa amidah pribadi). Ayat yang menggunakan terbanyak ialah (Osě shälom bimromāv bu ya'asĕ shälom aleynu v'al kol Yisrael v'imruamen).", yang bila diterjemahkan dalam Bahasa Indonesia adalab "Tuban yang membuat keamanan dalam keagungannya serta Tuhan-lah membuat keamanan di antara kita dan selurub rakyat Israel, Amin."; Perkataan Shalom digunakan secara meluas dalam lagu-lagu Israel yang populer seperti "In Our Garden", "Ratriti Sheteda", dan "Shalom Chaverim"; Presiden Amerika Serikat Bill Clinton menutup epilognya untuk Yitzhak Rabin dengan Shalom, chaver (Sampai jumpa lagi, sahabatku); Perkataan 'Lom (kadangkala Sh'lom) digunakan (terutama bagi para remaja Yahudi) sebagai singkatan untuk perkataan "Shalom" dalam bahasa gaul. Lihat http://id.wikipedia.org/wiki/Shalom 
taan yang berkaitan dalam Bahasa Ibrani modern termasuk l'shalem (ליל לים ) yang artinya "untuk bayar" dan shalem (לְ⿱ז) ) yang artinya "selesai".

Kata syalom yang berarti keselamatan menyangkut segala segi kehidupan, menyangkut relasi dengan Allah, relasi dengan sesama, dan relasi dengan keseluruhan ciptaan. Keselamatan juga dipahami hadir dalam situasi konkret meyangkut segi-segi kehidupan konkret, menyangkut situasi masyarakat yang ditandai dengan keadilan dan damai sejahtera. Imamat 26: 13 memberikan gambaran konkret mengenai situasi syalom ini, yaitu situasi yang ditandai dengan hasil bumi melimpah, negeri aman sentosa, tidak ada perang, musuh-musuh dikalahkan. ${ }^{19}$

"Dan Aku akan memberi damai sejabtera di dalam negeri itu, sehingga kamu akan berbaring dengan tidak dikejutkan oleh apapun; Aku akan melenyapkan binatang buas dari negeri itu, dan pedang tidak akan melintas di negerimu." 20

Keadaan Syalom ini dipandang sebagai berkat Allah dan berkaitan dengan perjanjian. Artinya, dari pihak umat dibutuhkan kesetiaan agar syalom itu tetap dirasakan. Oleh karena gambaran keselamatan terkait erat dengan perjanjian, nada umum keselamatan dalam Perjanjian Lama (PL) adalah keselamatan bagi umat Israel. Allah memberikan keselamatan-Nya hanya untuk umat Israel. Namun dalam PL juga muncul gagasan bahwa Allah mau menyelamatkan seluruh umat manusia. Dengan demikian meskipun belum menjadi tema sentral, keselamatan mulai dipikirkan sebagai keselamatan bagi semua orang. "Berpalinglah kepada-Ku dan biarkanlah dirimu diselamatkan, hai ujung-ujung bumi!. Sebab Akulah Allah dan tidak ada yang lain."22

Dalam kitab mazmur juga bahkan secara ekplisit menjelaskan dengan tegas tentang larangan melakukan kekerasan:

Pemfitnah tidak akan diam tetap di bumi, orang yang melakukan kekerasan akan diburu oleb malapetaka. Aku tabu, bahwa TUHAN akan memberi keadilan kepada orang tertindas dan membela perkara orang miskin. Sunggub, orang-orang benar akan memuji nama-Mu, orang-orang yang jujur akan diam dihadapan-Mu. ${ }^{23}$

Perjanjian Baru (PB) meneruskan gagasan PL mengenai keselamatan. Kata yang dipakai untuk mengungkapkan paham keselamatan dalam PB ialah soteria (penyelamatan) dan eirene (damai sejahtera, keselamatan). Hadirnya keselamatan di dunia diimani berkat Yesus Kristus dan Roh Kudus. Sementara itu, gambaran sosial-politik agak kurang mendapat tekanan, sementara kembalinya manusia kepada Allah lebih ditekankan. Keselamatan diartikan sebagai pengampunan dosa, pembebasan manusia dari kuasa dosa. Manusia diselamatkan berarti

${ }^{19}$ M.Purwatma, "Dosa dan Keselamatan”, dalam Nur Kholish Setiawan dan Djaka Soetapa (ed), Meniti Kalam Kerukunan .,370

${ }^{20}$ Imamat (26): 6

${ }^{21}$ Ibid dalam M.Purwatma

${ }^{22}$ Yesaya (45): 2

${ }^{23}$ Marmur (140):11-13/12-14 
manusia dipanggil kembali dalam relasi dengan Allah. Konsep inilah yang oleh Bapa Gereja awal kemudia diungkapkan dengan gagasan pengilahian, manusia diselamatkan berarti manusia dijadikan ilahi, ikut serta dalam keilahian Allah. ${ }^{24}$

Maka dari itu, dalam konteks kehidupan berbangsa dan bernegara yang berasaskan Pancasila, tentunya misi yang dibawa oleh Kristen (missionaris) atau dakwah yang dibawa oleh Islam adalah akumulasi kemanusiaan yang mengatasi individualitas dalam tataran integrasi seluruh kepentingan personal maupun kepentingan bersama melalui asas kemanusiaan. Karena kepentingannya adalah untuk seluruh manusia dan alam (rahmatan lil 'alamin) maka dalam menjalankan misi atau dakwah tidak ada lagi kecurigaan yang dapat menimbulkan konflik timbul karena orang tidak menghargai perbedaan. Orang menolak untuk member atau menerima bantuan karena alasan perbedaan, agama khususnya. Kelompok tertentu menutup mata terhadap kelompok lain yang sedang menderita, karena ia melihat kelompok tersebut adalah kelompok yang berbeda. Sering terjadi proses member terhadap pihak yang benar-benar membutuhkan/fakir miskin bahkan kepada orang yang terkena bencana alam terhambat karena berbeda.

Sehingga yang terjadi pada tahun 1992, misalnya di Nusa Tenggara Timur terjadi gejala fundamentalisme agama, ada pihak luar -pihak yang berkepentingan non-manusiawi - yang mengadakan provokasi secara beruntun terhadap masyarakat katolik di sana. Akibatnya umat Katolik, Protestan dan Islam saling berhadapan sebagai lawan, saling memusuhi. ${ }^{25}$

Agar tidak terjadi konflik dan kecurigaan seperti itu, mereka yang mendapat tugas khusus dalam misi atau dakwah semestinya pertama harus mengetahui ajaran-ajaran yang paling fundamental mengapa mereka diutus, diberikan tanggung jawab misi atau dakwah tersebut. Ketika sampai pada tatanan ini, maka semua agama - dalam koneks kajian khususnya agama Kristen dan Islam pasti akan menjawab untuk membebaskan manusia dari kesengsaraan, mendamaikan manusia serta menjadi rahmat bagi seluruh umat manusia.

\section{Penutup}

Secara normative, teks-teks agama bersifat ambivalen, ia bisa menebar kedamaian karena pesan-pesan suci perdamaiannya. Namun, ia juga rentan memicu kekerasan karena pesan-pesan tekstualitasnya "mengandung kekerasan". Jika teks tersebut ditafsirkan oleh kelompok radikal - dalam hal ini kelompok yang suka dengan kekerasan - maka teks beserta ajaran-ajaran agama pun akan berwajah keras, menyeramkan bahkan menakutkan. Islam dengan jargonnya "rahmatan lil'alamin", seyogyanya benar-benar menjadi rahmat, menyejukkan bagi siapapun yang ada disekitarnya bahkan benar-benar bagi seluruh alam. Baik ter-

\footnotetext{
${ }^{24}$ M.Purwatma, "Dosa dan Keselamatan”, dalam Nur Kholish Setiawan dan Djaka Soetapa (ed), Meniti Kalam Kerukunan .,371

${ }^{25}$ George Kirchberger, Dialog Dengan Masyarakat Pinggiran, (Ende: Nusa Indah, 1996)., hal. 112
} 
hadap sesama muslim, dengan non muslim bahkan kepada yang atheis sekalipun. Hal tersebut akan benar-benar tercapai jika setiap pemeluk agama - khususnya Islam - menempatkan spiritualitas yang universal dalam berkehidupan.

Setiap agama memiliki nilai-nilai yang khas, yang hanya terdapat pada masing-masing agama. Selain itu setiap agama juga memiliki nilai-nilai universal. Kita seharusnya tidak berpretensi menghilangkan nilai-nilai khusus dari agama, karena upaya seperti itu merupakan hal yang tidak mungkin kita hanya berupaya agar nilai-nilai khusus tersebut tetap berada dalam wilayah komunitas umat yang meyakininya.

\section{Daftar Pustaka}

Al Quran dan Al Kitab

Bahri, Syamsul, "Pro Kontra Aksi dan Makna Jihad", Media Dakwah edisi Dzulqaidah 1426/Desember 2005

Bolong, Bertolomeus, Paradigma Misi Kesejabteraan Islam \& Kristen, (Yogyakarta: San Juan, 2013).

Chirzin, Muhammad, "Jihad dalam Al-Quran Perspektif Modernis dan Fundamentalis", Hermeneia Vol. 2 Nomor 1, Januari-Juni 2003 (Yogyakarta: PPs. UIN Suka)

Jabir El-Jazair, Abu Bakar, Pola Hidup Muslim, (Bandung: Remaja Rosdakarya, 1990).

Kirchberger, Georg, Misi Gereja Dewasa Ini, (Maumere: LPBAJ, 1999). , Dialog dengan Masyarakat Pinggiran, (Ende: Nusa Indah, 1996).

Lewis, Bernard, Kemelut Peradaban Kristen, Islam dan Yabudi, terj. Prismasophie (Yogyakarta: IRCiSod, 2001).

Ruslani, Masyarakat Kitab dan Dialog Antaragama: Studi Atas Pemikiran Mohammed Arkoun, (Yogyakarta:Yayasan Bentang Budaya, 2000).

Setiawan, Nur Kholish dan Soetapa, Djaka (ed), Meniti Kalam Kerukunan : BeberapaIstilah Kunci dalam Islam dan Kristen (Yogyakarta: PT BPK Gunung Mulia, 2010).

Shihab, M. Qurash, Membumikan Al-Qur'an: Memfungsikan Wabyu dalam Kebidupan, Jilid 2 Jakarta: Penerbit Lentera Hati, 2011).

Watt, William Montgomy, Titik Temu ISLAM-KRISTEN, terj. Zaimudin (Jakarta: Gaya Media Pratama, 1996).

http://id.wikipedia.org/wiki/Shalom

http://www.koran-sindo.com

http://www.voaindonesia.com 